\title{
OLYMPIC GAMES COMPLEXITY MODEL (OGCM)
}

\author{
DIMITRIS GARGALIANOS,* KRISTINE TOOHEY,† AND DAVID K. STOTLAR \\ *Department of Physical Education \& Sport Sciences, Democritos University of Thrace, Komotini, Greece \\ †Department of Tourism, Sport \& Hotel Management, Griffith University, Queensland, Australia \\ $\ddagger$ School of Sport \& Exercise Science, University of Northern Colorado, Greeley, CO, USA
}

\begin{abstract}
The Olympic Games (OG) is a complex event project. This conceptual article aims at presenting the complexity of the Games by virtue of a three-dimensional, graphic model depicting the event's stakeholders and the interrelationships among them from the perspective of an Organizing Committee for the Olympic Games (OCOG). The model evolved from: a) content analysis of relevant literature (i.e., IOC organizational documents regarding the OCOG) and b) personal participation and observation of the authors in the organization of the Games. The model allows managers of OCOGs, especially those who do not have previous experience in Olympic matters, to quickly and comprehensively understand the complex and entwined organizational processes, as well the various stakeholder relationships that may not at first be readily apparent.
\end{abstract}

Key words: Olympic Games (OG); Complexity; Stakeholders

Introduction

As the Olympic Games (OG) have grown in size, cost, and scope, the processes of planning and delivering the event become increasingly more complex (Toohey \& Veal, 2007). They have concurrently become more technologically and media interdependent (Halbwirth \& Toohey, 2013), adding further layers of relationship management. The Games now require a wide variety of stakeholders to bid for, plan, and host the event (Parent, 2013).

The aim of this conceptual article is to present the complexity of the OG through a graphic model depicting the event's key stakeholders and to demonstrate the interrelationships between them from the perspective of an Olympic Games Organizing Committee (OCOG). In order to achieve this aim the authors discuss the complexity of sport events and specifically the OG in terms of their internal and external environments using extant literature. Then they present stakeholder theory, discuss its use in sport event research, and explain how it provides a theoretical basis for our model. The final section suggests the implications of the model for understanding theory and practice in event management and implications for future research.

From a theoretical perspective, it is important to understand Olympic stakeholders as managing in 
accordance with the tenets of stakeholder theory can allow organizations to achieve conventional corporate objectives as well as, if not better than, using alternative theoretically based approaches (Butterfield, Reed, \& Lemak, 2004; Donaldson \& Preston, 1995). From a practitioner perspective the model has utility as the OCOG human resources (paid staff, volunteers, contractors) play a highly significant role in planning, organizing, and delivering the event. Moreover, the majority of OCOG staff have not worked on a previous Games and thus do not immediately understand the relationships with the myriad of other organizations with which they will be involved. Thus, the sooner and more comprehensively they understand the complexity of the project, the better and quicker they are able to perform the tasks required of them and blend into the organizational culture (see McDonald, 1991). To that extent, one of the first and important priorities of an OCOG is to establish an in-house or outsourced process to train all new paid staff members and volunteers, and sometimes contractors as well, on general and specific issues regarding the OG (Athens 2004 Olympic Games Organizing Committee, 2005). However, as Emery (2010) notes, for major sport events "the primary focus of planning activity appears to be towards achievement of the financial bottom line ... without greater articulation, understanding, and shared commitment to a breadth of detailed outcomes, high levels of stakeholder satisfactions are unlikely to be realized" (p. 163).

This increased understanding is important, for as Frawley and Adair (2013) caution, the "Olympic Games is time constrained (with an absolute and nonnegotiable delivery date), resource constrained as to both total budget and number of employees, goal oriented, highly complex, and cross functional" (pp. 3-4). Thus, like any project, it is important for OCOG staff to understand the range of organizations and individuals who can positively and negatively affect the success of the Games. Emery's (2010) sport event management study identified that "the three most important critical success factors were knowledgeable staff, in-depth planning, sufficient and appropriate management of finance, and media” (p. 163). The first two of these factors are directly related to training.

One of the most effective and efficient ways of training is the use of models-that is, images or symbolic representation of abstract ideas (Bayman \& Mayer, 1988). Essentially, a model is something used to represent anything else. Chinn and Kramer (1999) characterize a model as "a complex mental formulation of experience” (p. 252). Constructing a model is also important theoretically as "in order for researchers to build strong, internally consistent typological theories it is critical that they understand the underlying models" (Doty \& Glick, 1994, p. 235). According to Kung and Solvberg (1986) a conceptual model should: enhance understanding of the representative system; assist efficient conveyance of system details between stakeholders; provide a point of reference for specifications; and document material for future reference and collaboration.

The Olympic Games Complexity Model (OGCM) presented in this article meets these criteria. It grew out of a review of related academic and Olympic organization's literature, and was informed by stakeholder theory, as well as the authors' observations and involvement with the OG staged between 2000 and 2012.

\section{Literature Review}

The OG organizational roles are codified by the International Olympic Committee (IOC), the governing authority of the Olympic Movement and controller of the rights to the Games. They are documented in the "Olympic Charter," which is reinforced by the "Host City Contract," a detailed document on OG managerial issues (Toohey \& Veal, 2007). Based on these documents the IOC's main goal is to improve its brand and generate increased revenues for the next editions of the Games, not just for itself but also other member organizations of the Olympic Movement (Payne, 2006). Such goals align with stakeholder theory, which accepts that an organization's success is achieved by producing valuable and agreeable outcomes across its range of stakeholders (Freeman, 1984).

It is not only the organizers of the event that have specific goals for their involvement. According to McDonnell, Allen, and O’Toole (1999) events are required to serve a multitude of agendas. It is no longer sufficient for an event to meet just the needs of its spectators. It must also embrace a plethora of other requirements including media specifications, 
sponsors' needs, community expectations, and government objectives. The last objective often includes economic growth (Preuss, 2000). For example, it was suggested that the 2012 Games would increase London's GPD by $£ 5.9$ billion in the period 20052016 and the total economic benefit was stated at $£ 1.9$ billion (Blake, 2005).

While event management and project management are different academic fields, each with their own field of knowledge, mega-sport event research has become informed by a number of different approaches (Frawley, 2011; Gold \& Gold, 2008; Horne \& Manzenreiter, 2002; Leonardsen, 2007). Gratton and Henry (1995) argue that management of major sports events is a very complex process and should be investigated as a separate entity. "Stakeholder" and "complexity" concepts are considered to be integral parts of such events. Stakeholders can be defined as "those groups without whose support the organization would cease to exist” (Freeman, 1984, p. 31).

The fact that managing the OG stakeholders is a highly complex task explains why the IOC awards the event to a city 7 entire years before its staging (Dubi, Hug, \& Van Griethysen, 2003). Immediately after the selection of the host city an OCOG is established to manage the event. In the course of its function the OCOG internally develops many different functional units and externally creates thousands of contractual relationships at local, state, national, and international levels, thus increasing the organizational complexity of the event.

Dooley (2002) describes organizational complexity as the degree of differentiation that exists within different elements constituting an organization. Marion and Bacon (2000) claim that "complex systems (i.e., an OCOG) are robust, involving multiple chains of interaction and causation” (p. 72). Managing an OCOG typically involves all elements of Maylor's (2003) definition of organizational complexity: a) organizational (people, departments, organizations, and nations involved), b) resource (time, capital, and processes involved), and c) technical (the level of innovation in the product or the project process).

Increased complexity of scale leads to intensification of demands on coordination, communication, and control of the project (Frawley, 2011). Slack and Parent (2006) reported that in many ways complexity is the most obvious feature of sport event organizations, because task and functional specialization leads to the creation of many jobs, which, in order to produce successful results, requires clear relationships and lines of communication. The people who organize events like the OG "inevitably face a steep learning curve by virtue of having to assemble from scratch the teams required to bring the Games to fruition" (Gold \& Gold, 2008, p. 303). Additional organizational complexities may also include having to rely upon large numbers of volunteers, who, in some cases, may constitute up to $95 \%$ of the workforce (Emery, 2002).

\section{Stakeholder Theory}

The theoretical framework of stakeholder theory provides a useful platform for understanding organizational complexity by analyzing internal and external organizational influences within their wider context (van Iterson, Mastenbroek, Newton, \& Smith, 2002). Donaldson and Preston (1995) argue that stakeholder theory has descriptive, instrumental, and normative aspects. Essentially, stakeholder theory has become an umbrella term for management theories relating to explaining stakeholders' relationships with an organization and the reverse. While stakeholder theory has evolved and diversified since its introduction in the 1960s, its core concept has centered on the premise that an organization's success is determined by its ability to take into account the needs, goals, and motivations of the key organizations and individuals with which it interacts (i.e., its stakeholders) (M. Friedman, Parent, \& Mason, 2004). These stakeholders can include a firm's employees, customers, suppliers, stockholders, banks, governments, and other groups who can either assist or impede the organization achieve its goals (Freeman, 1984).

While the term "stakeholder" first appeared in academic literature in the 1960s, stakeholder theory first gained real credibility in the 1970 s. From its initial theoretical foundation the stakeholder concept quickly broadened to be used in management literature pertaining to corporate planning, systems theory, corporate social responsibility, and organizational theory (Freeman, 1984). The first and latter streams of literature are the most pertinent to this article. Corporate-planning literature 
is concerned with ensuring that an organization's plans and policies are effective by developing techniques for identifying its capabilities, resources, environmental opportunities, and emerging strategic issues and problems (Freeman, 1984). Organizational theory literature is broader than this in that it seeks to explain organization-environment relationships. For example, "from an organizational theory perspective, a project can be seen as being constituted from the entire set of relationships it has with itself and with its stakeholders” (Maylor, Vigden, \& Carver, 2008, pp. 22-23).

Thus, since its introduction, stakeholder theory has changed business paradigms from the premise that businesses should solely serve the interests of their owners or shareholders. Instead, stakeholder theorists have argued that the interests of other stakeholders, such as the public, community, or employees, or more broadly, internal and external influences, are important considerations that need to be managed. Even more dramatically, the theory suggests that stakeholders include "nontraditional stakeholder groups who are usually thought of as having adversarial relationships with the firm” (Freeman, 1984, p. 38).

To that extend, stakeholder theory provides a suitable theoretical framework to examine an OCOG's internal and external environments. From a practitioner viewpoint, it allows the OCOG staff to determine the groups and individuals with which it must interact.

\section{Stakeholder Theory and Mega-Sport Contexts}

The first, and perhaps most important, lesson to be drawn from the literature is that stakeholder theory is applicable to research in mega-sport contexts. Pfeffer and Salanick (1978, cited in Freeman, 1984) suggest that: "organizations survive to the extent that they are effective. Their effectiveness derives from the management of demands, particularly the demands of interest groups upon which the organizations depend for resources and support” (p. 42).

M. Friedman et al. (2004) suggest that all sport organizations:

Have a variety of groups and individuals whose relationships with the organization are based on certain objectives. Each of these stakeholders has differing abilities to achieve its goals. As such, managers need to meet the needs of those within their constituent environment or risk losing their support and/or participation, which could threaten the organization's success or even its existence. (p. 171)

However, they caution that not all stakeholders are equally important and "sport managers can benefit from a robust and systematic method of stakeholder prioritization based in the assessment of situational factors” (M. Friedman et al., 2004, p. 171).

Parent (2005, 2008) and Parent and Seguin (2007) believe that stakeholders are vital to mega-sport event organizers; moreover, event organizers need to invest considerable financial and human resources in order to effectively manage, mitigate possible internal and external organizational conflicts, and secure the support of their diverse range of stakeholders.

There have been a number of studies that have categorized sport event stakeholders; however, these categories have not been presented graphically as a model. McDonnell et al. (1999) examined stakeholders from a functional perspective categorizing them according to their relationship with the event. Shone and Perry (2001) categorized event stakeholders based on their industry sectors as either public, private, and voluntary. A. L. Friedman and Miles (2004) and Frawley (2011) categorized event stakeholders as cooperative (provide opportunities), competitive (potentially represent a threat) (Freeman, 1984), adversarial (may actively seek to harm the organization), voluntary, or involuntary.

As mega-sport event stakeholders influence the success of the event's organization (Lesjo, 2000) it is important for the event's owners to know the extent of all the above categories of stakeholders, consider the relationships with them, and portray these relationships in an easy to understand way. A visual model serves this purpose.

\section{Presentation of the OGCM}

Acknowledging that "almost all social science research proceeds by building simplified representations of social phenomena” (Gilbert \& Terna, 2000, p. 57), the OGCM grew out of reading the literature and was further informed by stakeholder theory, as well as the authors' observations, experiences, and involvement with various editions of OG as organizational insiders. This is significant because insider 
research can assist in revealing the complexity and depth of the social and organizational interactions in the case organizations (Veal, 2006), and insiders can use the organizational knowledge and understanding they acquired to inform their analysis (Coghlan, 2003). Although the model presented in this article is OG specific, its principles could be applied to the organizing committees of other mega-events as well (i.e., Commonwealth Games, Asian Games, etc.).

In order for an OCOG to organize the Games it has to create a huge internal and external network of individuals and groups/organizations (either already existing, or created just to serve the Games) as stakeholders who need to cooperate efficiently in order to perform specific activities, towards attaining specific goals, following a rigid timetable, and using predetermined budgets (Frawley, 2011). This network was conceptualized and expressed in the form of a three dimensional, iceberg-like, graphic model (Fig. 1). The tip of the iceberg represents the athletes (the visible part of the OG "iceberg"), followed by the coaches (they prepare the athletes) and the referees/officials (they officiate the contests/games), the mass media (they communicate the event around the globe), and the sponsors (they support the event in multiple ways).

The network is comprised of the:

1. Olympic sports and their subdisciplines,

2. International Federations (IFs), which work closely with their national counterparts towards organizing the Olympic sports,

3. Competitive (i.e., stadiums, arenas, swimming pools, gymnasiums, etc.), as well as the noncompetitive (i.e., airports, train/bus stations, hospitals, hotels, etc.) venues,

4. OCOG's functional areas (FAs) (for a full list see the Appendix).

5. Olympic Inc. entities (i.e., companies, institutions, etc.) established for the implementation of certain projects (i.e., transportation, etc.),

6. NOCs, which coordinate the participation of their countries' athletes in the Games (http:// www.olympic.org).

Moreover, the network includes:

7. State/federal ministries involved in the organizational process,
8. Volunteers, and,

9. Olympic spectators.

The lines connecting all parts of the model represent the continuous communication that has to be developed between all stakeholders. A disruption at any point in the model at any time has the potential to disturb every organizational member/process involved. For example, let's assume that although he is registered to participate in the Games, a top level athlete from a country other than the host country does not arrive at the airport with the other members of the team. According to the guidelines established for such an occasion the OCOG staff member who is responsible to welcome the team immediately notifies all persons/processes involved and need to know (i.e., "NOC Services," "Accreditation," “Athletes' Village Services,” etc.) in order for appropriate actions to be initiated.

Implications of the Model for Theory and Practice

The staging of an OG requires meticulous planning, efficient organization, and management of resources across local, national, and international levels, and sensitive stakeholder management (Guttmann, 2002; Searle, 2002; Toohey, \& Veal, 2007). The model presented in this article describes the stakeholders of an OG and the relationships between them. In the beginning of the organizing process they function relatively independently, accomplishing their individual tasks. As the time progresses the level of cooperation between them increases and during Games time they consolidate their individual missions to a unified effort. During this process reciprocal influences on a variety of factors (i.e., power, authority, possession/dissemination of information, attitudes, etc.) induce changes to the behavior of the interacting entities.

As complexity increases organizational members are increasingly barraged with demands requiring their attention-they solve arising problems and scan for new ones. This taxes the information processing capacity of the organization and individuals tend to shut down, saving their energy for emergency needs that may arise (Dooley, 2002; Frawley, 2011). In order to reduce the stress of the information overload organizational members may respond in a variety of ways, like greater tolerance of 

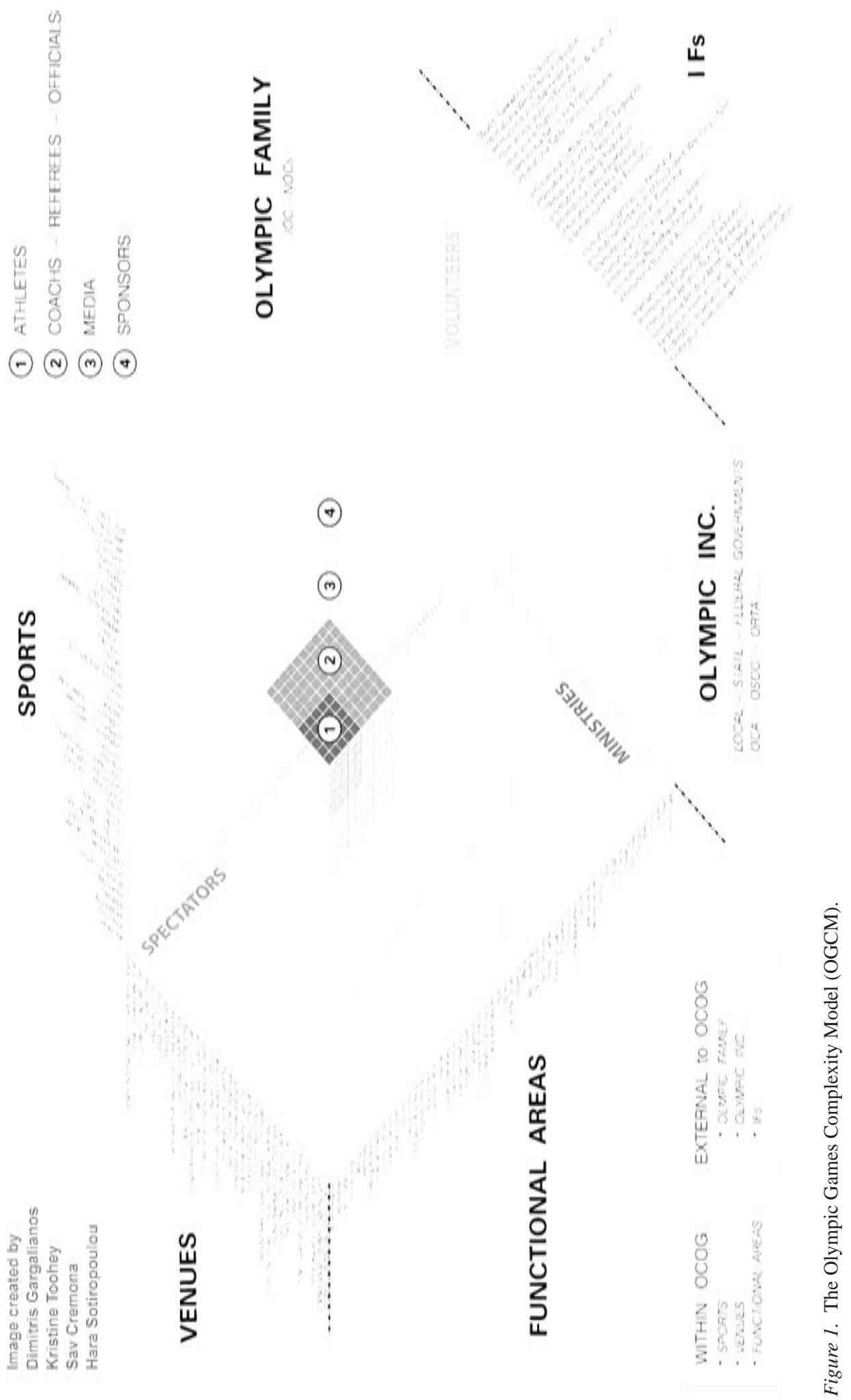
error, filtering, abstracting, and use of multiple channels (Weick, 1995). General and job specific training provides organizational members with valuable information to understand what the project is about, where they fit in, and what is required of them, thus not only reducing job-related stress but also increasing performance and productivity.

A conceptual model's primary objective is to convey the fundamental principles and functionality of the system it represents (Kung \& Solvberg, 1986). According to Freeman (1984), “an organization’s stakeholder management capability is determined by its ability to understand its conceptual map of stakeholders, the processes for dealing with these stakeholders and the transactions it uses to achieve organizational objectives with stakeholders” (p. 74). Thus, from a theoretical perspective, a stakeholder map can position the OCOG as "an organizational entity through which numerous and diverse participants accomplish multiple, and not always entirely congruent, purposes” (Donaldson \& Preston, 1995, p. 70).

As the organization of an event, the size of the OG is shaped and impacted by both internal and external organizational characteristics (Frawley \& Adair, 2013). The practical implication of the OGCM presented in this study is that it allows OCOG managers, especially those who do not have previous experience in Olympic matters, as well as the other Olympic stakeholders, to quickly and comprehensively understand the complex and entwined organizational processes that may not be readily apparent. This understanding could increase their confidence, improve their performance, and produce considerable savings of resources in the form of better decisions, as well as in the form of fewer and less significance mistakes. As Freeman (1984) states:

An organization which understands its stakeholder map and the stakes of each group, which has organizational processes to take these groups and their stakes into account routinely as part of the standard operating procedures of the organization and which implements a set of transactions or bargains to balance the interests of these stakeholders to achieve the organization's purpose, would be said to have high (or superior) stakeholder management capability. (p. 53)

In conclusion, the OGCM's utility is that it allows a visual representation of the complexity of stakeholders, as suggested by M. Friedman et al. (2004). Moreover, it advances the conceptualization of an organization's stakeholders by presenting them as a three-dimensional, interconnected network, which has not been presented before as an OCOG's map, supporting Mahbubur, Meenar, and Ambrus' (2006) argument that three-dimensional simulation communicates more effectively than twodimensional representations. Finally, the OGCM could assist students and researchers of event and or project management to portray this multifaceted entwining of relationships in their research.

\section{Appendix: OCOG's Functional Areas}

Each of the following functional areas breaks down to smaller units according to needs (OCOG Sydney 2000, introduction seminar).

Sport, Accommodation, Accreditation, Administration, Broadcasting, Catering, Ceremonies, Consumer Products, Creative Services/Image of the Games, Cleaning \& Waste, Communication \& Community Relations, Competition/Training Venues, Corporate Services, Cultural Program, Customs, Doping Control, Emergency Services, Environment, Finance, Football Tournament, Foreign Language Services, Games Coordination, Games Integration, Government Relations, Headquarters Management, Human Resources Management, Information Services, Internal Communication, International Federations' Relations, International Judges-Referees, Legal, IOC Relations \& Protocol, Marketing, Medical Services, NOC Relations, Official Products, Overlays, PostGames Jobs, Post- Games Report, Procurement/ Logistics, Publications, Risk Management, Security, Special Events, Spectator Services, Sponsorship, Technology, Test Events, Ticketing, Torch Relay, Transfer of Olympic Knowledge, Transportation, Uniforms, Villages (Athletes, Media, Technical Officials, Grooms), Volunteers, Written Press Operations, and any other each OCOG considers necessary.

\section{References}

Athens 2004 Organising Committee for the Olympic Games. (2005). Official report of the XXVIII Olympiad, Vol. 1. Athens: Author.

Bayman, P., \& Mayer, R. (1988). Using conceptual models to teach basic computer programming. Journal of Educational Psychology, 80(3), 291-298. 
Blake, A. (2005). The economic impact of the London 2012 Olympics. Retrieved August 10, 2011, from http://utsescholarship.lib.uts.edu.au/dspace/bitstream/ handle/2100/994/Impact\%202005_5.pdf?sequence=1

Butterfield, K. D., Reed, R., \& Lemak, D. J. (2004). An inductive model of collaboration from the stakeholder perspective. Business \& Society, 43(2), 162-195.

Chinn, P., \& Kramer, M. (1999). Theory and nursing: A systematic approach. St. Louis: Mosby.

Coghlan, D. (2003). Practitioner research for organizational knowledge: Mechanistic and organistic oriented approaches to insider action research. Management Learning, 34(4), 451-463.

Donaldson, T., \& Preston, L. (1995). The stakeholder theory of the corporation: Concepts, evidence and implications. Academy of Management Review, 20(1), 65-91.

Dooley, K. (2002). Organizational complexity. In M. Warner (Ed.), International encyclopedia of business and management (pp. 5013-5022). London: Thompson Learning.

Doty, D. H., \& Glick, W. H. (1994). Typologies as a unique form of theory building: Toward improved understanding and modeling. The Academy of Management Review, 19(2), 230-251.

Dubi, C., Hug, P. A., \& Van Griethysen, P. (2003). Olympic Games management: From candidature to the final evaluation, an integrated management approach. In M. Moragas, C. Kennett, \& N. Puig (Eds.), The legacy of the Olympics Games 1984-2000 (pp. 403-414). Lausanne: IOC.

Emery, P. R. (2002). Bidding to host a major sports event: The local organizing committee perspective. International Journal of Public Sector Management, 15(4), 316-335.

Emery, P. (2010). Past, present, future major sport event management practice: The practitioner perspective. Sport Management Review, 13(2), 158-170.

Frawley, S. (2011). Organizing sport at the Olympic Games: The case of Sydney 2000. Unpublished Ph.D., The University of Technology, Sydney.

Frawley, S., \& Adair, D. (2013). Managing the Olympic Games. Basingstoke, Hampshire, UK: Palgrave Macmillian.

Freeman, R. (1984). Strategic management: A stakeholder approach. Boston, MA: Pitman.

Friedman, A. L., \& Miles, S. (2004). Stakeholder theory and communication practice. Journal of Communication Management, 9(1), 89-97.

Friedman, M., Parent, M., \& Mason, D. (2004). Building a framework for issues management in sport through stakeholder theory. European Sport Management Quarterly, 4(3), 170-190.

Gilbert, N., \& Terna, P. (2000). How to build and use agentbased models in social science. Mind \& Society, 1(1), 57-72.

Gold, J., \& Gold, M. (2008). Olympic cities: Regeneration, city rebranding and changing urban agendas. Geography Compass, 2(1), 300-318.

Gratton, C., \& Henry, I. (1995). Sport in the city. The role of sport in economic and social regeneration. London: Routledge.
Guttmann, A. (2002). The Olympics: A history of the modern Games. Chicago, IL: University of Illinois Press.

Halbwirth, S., \& Toohey, K. (2013). Information, knowledge and the organisation of the Olympic Games. In S. Frawley \& D. Adair, D. (Eds.), Managing the Olympic Games (pp. 33-49). Basingstoke, Hampshire, UK: Palgrave Macmillian.

Horne, J., \& Manzenreiter, W. (2002). Japan, Korea and the 2002 World Cup. London: Routledge.

Kung, C., \& Solvberg, H. (1986). Activity modeling and behavior modeling. In T. Olle, H. Sol, \& A. VerrijnStuart (Eds.), Proceedings of the IFIP WG 8.1 working conference on information systems design methodologies: Improving the practice (pp. 145-171). Amsterdam: North-Holland Publishing Co.

Leonardsen, D. (2007). Planning of mega events: Experiences and lessons. Planning Theory \& Practice, 8(1), 11-30.

Lesjo, J. H. (2000). Lillehammer 1994: Planning, figurations and the "green" Winter Games. International Review for the Sociology of Sport, 35(3), 282-293.

Mahbubur, M., Meenar, R., \& Ambrus, A. (2006). Threedimensional models encourage public participation. ArcUser Online. Retrieved October 9, 2013, from http:// www.esri.com/news/arcuser/0506/3dmodel1of2.html

Marion, R., \& Bacon, J. (2000). Organizational extinction and complex systems. Emergence, 1(4), 71-96.

Maylor, H. (2003). Project management (3rd ed.). Harlow, UK: FT Prentice Hall.

Maylor, H., Vidgen, R., \& Carver, S. (2008). Managerial complexity in project-based operations: A grounded model and its implications for practice. Project Management Journal, 39(Supplement), S15-S26.

McDonald, P. (1991). The Los Angeles Olympic Organizing Committee: Developing organizational culture in the short run. In P. Frost (Ed.), Reframing organizational culture (pp. 26-38). Newbury Park, CA: Sage.

McDonnell, I., Allen, J., \& O’Toole, W. (1999). Festivals and special events management. Sydney: Wiley \& Sons Australia.

Parent, M. (2005). Large-scale sporting events: Organizing committees and stakeholders. Unpublished Ph.D., University of Alberta, Edmonton, Alberta.

Parent, M. (2008). Evolution and issue patterns for major sport event organizing committees and their stakeholders. Journal of Sport Management, 22(2), 135-164.

Parent, M. (2013). Olympic Games stakeholder governance and management. In S. Frawley \& D. Adair (Eds.), Managing the Olympic Games (pp. 15-32). Basingstoke, Hampshire, UK: Palgrave McMillian.

Parent, M., \& Seguin, B. (2007). Factors that led to the drowning of a world championship organising committee: A stakeholder approach. European Sport Management Quarterly, 7(2), 187-212.

Payne, M. (2006). Olympic turnaround: How the Olympic Games stepped back from the brink of extinction to become the world's best known brand. Westport, CT: Praeger Publishers. 
Pfeffer, J., \& Salancik, G. R. (1978). The external control of organizations: A resource dependence perspective. New York, NY: Harper and Row.

Preuss, H. (2000). Economics of the Olympic Games: Hosting the Games 1972-2000. Sydney: Walla Walla Press.

Searle, G. (2002). Uncertain legacy: Sydney’s Olympic stadiums. European Planning Studies, 10(7), 845-860.

Shone, A., \& Perry, B. (2001). Successful event management: A practical handbook. London: Continuum.

Slack, T., \& Parent, M. (2006). Understanding sport organizations: The application of organizational theory (2nd ed.). Champaign, IL: Human Kinetics.
Toohey, K., \& Veal, A. J. (2007). The Olympic Games: A social science perspective (2nd ed.). Wallingford, Oxon, UK: CABI Publishing.

van Iterson, A., Mastenbroek, W., Newton, T., \& Smith, D. (2002). The civilized organization: Norbert Elias and the future of organization studies. Amsterdam: John Benjamin.

Veal, A. J. (2006). Research methods for leisure and tourism: A practical guide (2nd ed.). Sydney: Prentice Hall.

Weick, K. (1995). Sensemaking in organizations. Thousand Oaks, CA: Sage. 